\title{
O POTENCIAL DAS AVENIDAS DE FUNDO DE VALE PARA RECEBER A INFRAESTRUTURA VERDE-AZUL
}

\author{
THE POTENTIAL OF AVENUES OF VALLEY FLOOR TO RECEIVE \\ BLUE-GREEN INFRASTRUCTURE
}

\author{
taícia Helena Negrin Marques \\ Arquiteta e Urbanista pela PUC-Campinas, Msc Arquitetura da Paisagem e Planejamento pela \\ Universidade de Wageningen - Holanda, Doutoranda pela FAU-USP, \\ Departamento Paisagem e Ambiente \\ e-mail: marques.taicia@usp.br
}

\begin{abstract}
RESUMO
Muitas das avenidas de São Paulo foram instaladas em áreas de fundo de vale. Frente aos atuais desafios ambientais, essas áreas surgem como potenciais para receber Infraestruturas Verde- Azuis, capazes de fornecer diversos serviços ecossistêmicos à cidade. $O$ presente artigo apresenta os resultados de análises geoespaciais das bases de dados fornecidas pelo município de São Paulo (Geosampa), quanto à proporção de rios e córregos canalizados e vias em áreas de várzea na cidade. Além disso, apresenta o método multicriterial que vem sendo construído para a análise das avenidas em fundo de vale compreendidas no Transecto de Estudo delimitado pelo projeto aprovado pela Fapesp: "Infraestrutura Verde para a Resiliência Urbana às Mudanças Climáticas da cidade de São Paulo" (FRANCO, M.A.R., 2015), quanto ao seu potencial para receber as intervenções de Infraestrutura Verde- Azul. $O$ estudo apresentando faz parte das primeiras análises elaboradas para o desenvolvimento da tese doutoral da autora (em andamento).
\end{abstract}

Palavras-chave: Infraestrutura Verde-Azul; Infraestrutura Verde; Paisagem como Infraestrutura; Avenidas em fundo de vale; Cidade como Ecossistema 


\begin{abstract}
Many avenues in São Paulo City have been built in areas of valley floors. Confronted with the current environmental challenges, those areas present a potential to receive Green-Blue infrastructures, able to provide several ecosystem services to the city. This article presents the results of geospatial analysis of the databases provided by the city authorities (Geosampa), regarding the proportion of channelled rivers and streams as well as roads in floodplain areas inside the city. In addition, it presents the multicriteria method which is being constructed to analyze the valley floor avenues considered in the Study Transect delimited by the project approved by FAPESP: "Green Infrastructure for Urban Resilience to Climate Change in the City of São Paulo" (FRANCO, MAR, 2015), regarding its potential to receive the interventions of Green-Blue Infrastructure. This stu$d y$ is part of the preliminary analysis elaborated for the development of the doctoral thesis of the author (in progress).
\end{abstract}

Keywords: Green-Blue Infrastructure; Green Infrastructure; Landscape as Infrastructure; Valley Floor Avenues; City as Ecosystem

\title{
INTRODUÇÃO
}

São Paulo acompanhou um crescimento urbano desordenado e rápido durante o século XX, com um fluxo migratório intenso devido à expansão da industrialização no país (BRITO, F.e SOUZA, J. 2005, p. 49). A instalação de infraestruturas capazes de suprir as necessidades das milhares de pessoas que chegavam a este centro urbano levou à redução drástica de suas áreas verdes, à canalização e enterramento de muitos de seus rios e córregos, distanciando a população dos cursos d'água e promovendo a ocupação extensiva das várzeas. De forma geral, as infraestruturas foram pensadas como sistemas centralizados, rígidos e monofuncionais destinados a fornecer um único serviço (FARR, 2008). Tampouco foram considerados o funcionamento e as dinâmicas dos sistemas ambientais intrínsecos às paisagens existentes e o sistema de áreas verdes e hídrico natural foi desconfigurado (HERZOG, C.P. e ROSA, L. Z., 2010).

Impulsionados por planos urbanos sanitaristas e hidráulicos, as várzeas, responsáveis pela retenção e condução lenta das águas de chuva, receberam tubulações subterrâneas com o objetivo de coletar e afastar o mais rápido possível as águas pluviais e residuais e 
assim, minimizar os riscos de alagamentos e doenças. A urbanização das várzeas também foi fortemente influenciada pelo Plano de Avenidas, publicado em 19301. Tendo no transporte automobilístico o suporte de desenvolvimento da cidade, o plano propunha uma rede de avenidas, como pode ser visto na Figura 01, disposta de forma radial e perimetral, muitas delas instaladas nas áreas mais planas das várzeas dos rios meandrosos da cidade (Figura 02), como as avenidas marginais dos rios Tietê e Pinheiros, reforçando assim a prática de canalização e urbanização de fundos de vale (TRAVASSOS,L. 2010, p. 22-23).

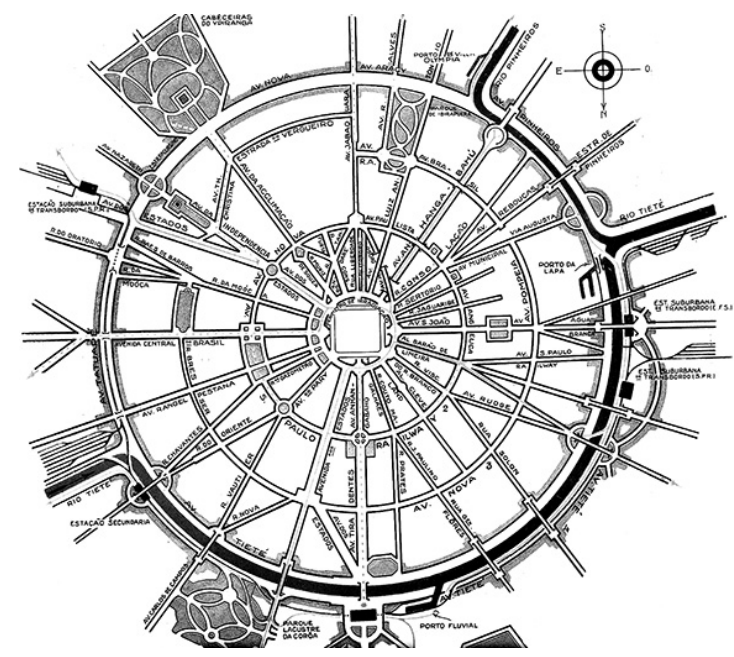

Figura 01 - "Esquema Teórico para São Paulo no Plano de Avenidas" de Prestes Maia e Ulhôa Cintra - 1930. Fonte: TOLEDO, B. L (1996).

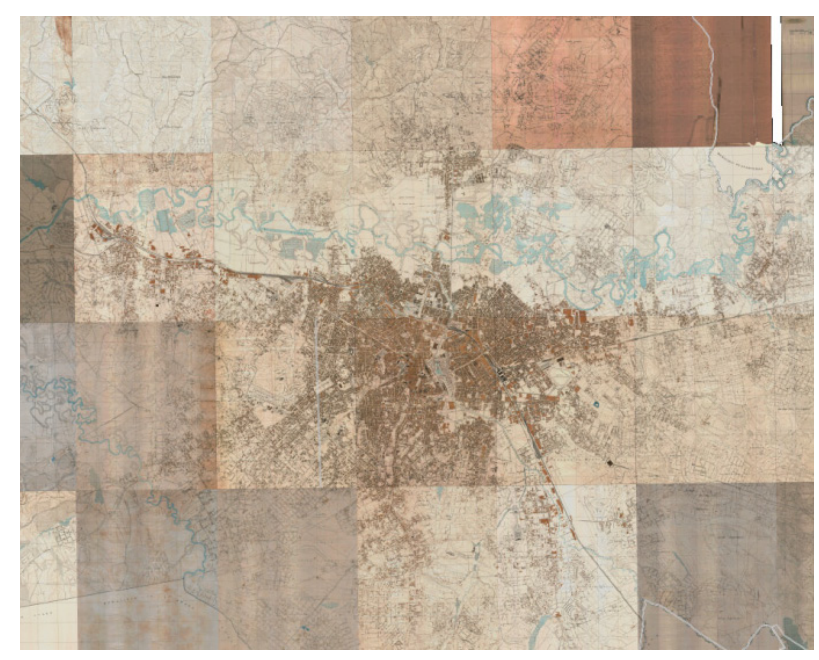

Figura 02 - Mapa de 1930, com os rios Tietê e Pinheiros ainda meandrosos. Fonte: SARA Brasil (1930)

Como suporte ao crescimento urbano contínuo de São Paulo, as avenidas radiais foram desenhadas de forma a conectar as zonas centrais àquelas periféricas, onde ainda persistem as duas principais unidades de conservação de São Paulo, da Serra da Cantareira, a norte, e da Serra do Mar, a sul. Durante as décadas seguintes a 1930 outros planos e programas, como por exemplo o Procav² $^{2}$ (1987), reforçaram a ocupação das várzeas por vias e canalizações. Atualmente, mesmo com propostas e planos de abrangência regional e municipal que questionam a canalização de córregos, o modus operandi da década de 1930 ainda predomina ao longo de grande parte dos fundos de vale da cidade (TRAVASSOS,L. 2010, p. 23).

\footnotetext{
1 "Plano de Avenidas para a Cidade de São Paulo" Elaborado pelo energenheiro Francisco Prestes Maia e publicado em 1930.

${ }^{2}$ Procav - Programa de Canalização e Implantação de vias de fundo de vale (1987)
} 
Como resultado desse processo as ameaças ambientais, tanto nas unidades de conservação, devido ao espraiamento urbano, quanto nas áreas mais consolidadas, devido à falta de áreas verdes e azuis permeáveis ao tecido urbano, passaram a ser cada vez mais visíveis e afetar diretamente a qualidade de vida das pessoas. A poluição intensiva das águas, por cargas difusas ${ }^{3}$ e pontuais ${ }^{4}$, reflete essa ameaça e resulta na busca desse recurso com qualidade potável em lugares cada vez mais distantes.

Impactadas tanto pelo uso do solo quanto por fenômenos globais, as próprias infraestruturas vem se tornando ineficientes e obsoletas. Segundo o Intergovernmental Panel on Climate Change as mudanças climáticas esperadas irão resultar na falência das infraestruturas tradicionais (IPCC, 2014). Quando estas mudanças irão ocorrer é difícil dizer, porém seus efeitos já começam a ser sentidos, por exemplo a partir principalmente do segundo semestre de 2012, quando a cidade de São Paulo passou a enfrentar o paradoxo de ter bons índices de chuva local, contar com uma vasta rede de rios e córregos, porém, devido à estiagem na área das principais represas de abastecimento, enfrentar sua pior crise hídrica, trazendo graves consequências sociais, econômicas e políticas para a maior economia do país.

Surge aí a necessidade, e ao mesmo tempo a oportunidade, de se repensar São Paulo a partir de suas infraestruturas. Não mais deterministas, mas flexíveis, que possam se adaptar a fenômenos climáticos cada vez mais difíceis de prever e posicionar a problemática das águas não apenas como uma questão hidráulica, mas sim urbana e de paisagem.

Neste sentido, o presente artigo apresentará o resultado de análises iniciais feitas por geoprocessamento a partir das bases de dados fornecidas pela Prefeitura Municipal de São Paulo (PMSP), via Geosampa, tanto para a escala da cidade, quanto para a área delimitada pelo transecto de estudo referente ao projeto aprovado pela Fapesp:

\footnotetext{
3 "A poluição por cargas difusas se origina (...) com o arraste dos poluentes pelas precipitações e posterior transporte pelo escoamento superficial e, por esta razão, é um fenômeno de natureza aleatória(...) Os problemas decorrentes da poluição difusa são de natureza qualitativa e quantitativa. (PMSP, 1999, p. 269)

4 "(...)decorrentes de lançamentos de esgotos domésticos não tratados e efluentes industriais". (PMSP, 1999, p. 264)
} 


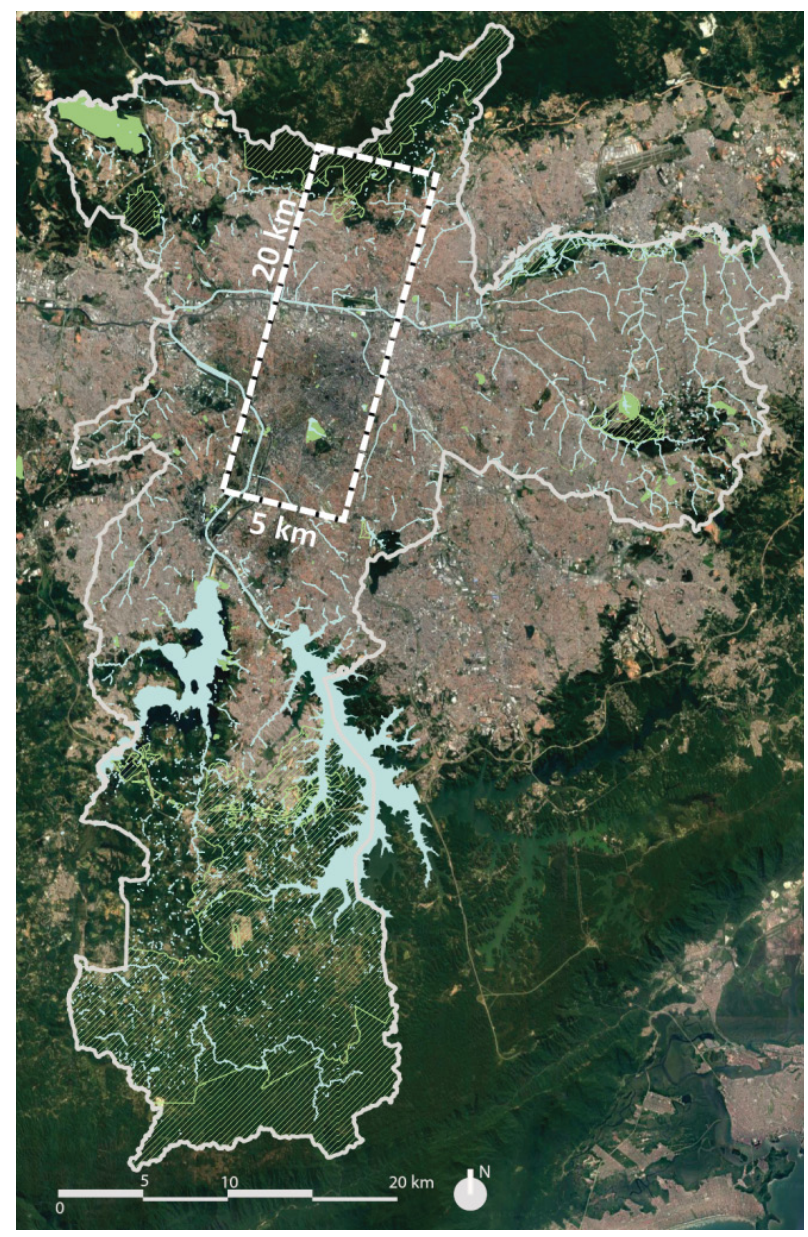

"Infraestrutura Verde para a Resiliência Urbana às Mudanças Climáticas da cidade de São Paulo" (FRANCO, M.A.R., 2015) $)^{5}$. O objetivo destas análises foi dar início à elaboração de uma ferramenta capaz de auxiliar a tomada de decisão quanto à identificação de avenidas de fundo de vale com maior ou menor potencial para receber Infraestruturas Verde- Azuis. Os critérios utilizados relacionam a condição física dos córregos e a conexão direta ou indireta das avenidas com áreas verdes do tipo parque. O presente artigo faz parte das primeiras análises efetuadas pela autora, relacionadas ao desenvolvimento de sua tese doutoral.

Figura 03 - Localização área do Transecto de Estudo. Elaboração: autora

\section{PAISAGEM COMO INFRAESTRUTURA VERDE-AZUL}

Podemos resgatar abordagens ecológicas propostas no século XIX por Frederick Law Olmsted, a partir da criação de sistemas de parques urbanos que cumpriam funções ambientais, infraestruturais, e socio-culturais. lan McHarg nos anos 60, (MCHARG, I. 1969) reforça esses ideiais e, diante de cidades norte americanas cada vez mais consolidadas, propõe a utilização de sistemas naturais como estratégia de desenho e planejamento regional. Somados a estes conceitos, a utilização de definições biológicas como metabolismo e ecossistema, passaram a dar o apoio necessário para que

\footnotetext{
5 "Como resultados, esta pesquisa produzirá métodos e procedimentos de planejamento ambiental e projeto sustentável, na escolha e implementação de áreas estratégicas, para uma rede de infraestrutura verde eficiente para a 'cidade resiliente'". Coordenado pela Profa. Dra. Maria de Assunção Ribeiro Franco (FRANCO, M. A. R., 2015)
} 
a cidade contemporanea pudesse ser tratada como parte integral do meio ambiente (FRANCO, M.A.R., 2003). Esse processo corroborou para a ampliação da disciplina de Arquitetura da Paisagem e a deixaram cada vez mais multidisciplinar.

A cidade vista como um ecossistema dinâmico e complexo (TJIALLINGII, S. P., 1993 apud NEWMAN, P.W.G., 1999), se interconecta com outros ecossistemas e assim como tal, possui um metabolismo, ou seja, recebe entradas (inputs) de materiais, água e energia e produz resíduos (outputs). A grande diferença é que a cidade moderna vinha tratando o seu metabolismo de forma linear, ou seja, todos os recursos que entravam em seu meio eram consumidos uma única vez e então descartados enquanto no meio natural, o descarte de um produto (output) por um organismo é utilizado como alimento (input) por outro, formando uma cadeia complexa de benefícios multiplos e ciclos fechados de nutrientes (TJIALLINGII, S. P., 1993 apud NEWMAN, P.W.G., 1999).

Charles Waldheim analisa conjuntamente os aspectos da paisagem, ecologia e urbanismo contemporâneo e propõe um manifesto onde apresenta o conceito Paisagismo Urbanístico (Landscape Urbanism), afirmando que: "a Arquitetura da Paisagem vem se tornando uma lente através da qual a cidade contemporânea é representada e um meio pelo qual é construída" (WALDHEIM, C., 2006, p. 15). O arquiteto paisagista Jusuck Koh, incrementa esse posicionamento alegando que o paradigma infraestrutural seja quebrado pela aplicação de Infraestruturas Ecológicas, e reforça o objetivo de buscar um planejamento sustentável, multiescalar e evolutivo que não considera as cidades como entidades isoladas ou segregadas da natureza, mas sim como entidade única, como um único ecossistema $(\mathrm{KOH}, 2011)$. A Infraestrutura Ecológica seria capaz de conectar áreas naturais isoladas através de uma paisagem metropolitana cada vez mais fragmentada (AHERN, 1995).

Somando e discutindo o Paisagismo Urbanístico e as Infraestruturas Ecológicas, Bélanger (2013) defende voltarmos a pensar a Paisagem como Infraestrutura (Landscape Infrastructure) como estratégia do urbanismo superar os métodos de engenharia civil que dominaram o desenho desses sistemas de forma centralizada, monofuncional e não resiliente.

Nos contextos urbanos consolidados como o da cidade de São Paulo, esses conceitos são atrelados aos novos desafios das redes e sistemas, onde a própria infraestrutura surge como uma estratégia de transição de um sistema rígido, monofuncional e centralizado para um sistema complexo, multifuncional e flexível, capaz de se adap- 
tar a cenários futuros difíceis de prever. Essa infraestrutura, retoma os conceitos de Olmsted e das Infraestruturas Ecológicas e relaciona meio urbano e não urbanizado. Ao assumir uma postura mais integrada à paisagem e ao ambiente e, portanto, mais "verde" permeia o tecido urbano e cria um mosaico de áreas verdes que impacta o uso e a ocupação do solo ao longo do tempo (AHERN, J. 2007).

Oferecendo serviços ecossistemicos, essa rede verde pode por exemplo, beneficiar o ciclo da água urbana, melhorar o microclima e o metabolismo das cidades, beneficiando a vida das pessoas, enriquecendo a fauna e a flora e reconectando ecossistemas. Esses preceitos formam a base da Infraestrutura Verde (IV), uma ferramenta que vem ganhando espaço dentre os arquitetos de paisagem, planejadores e disciplinas afins, preocupados tanto com suas aplicações mais conservacionistas, como aquelas propostas por BENEDICT e MCMAHON (2006), quanto àquelas mais focadas em suas possibilidades nas áreas urbanas, defendidas por exemplo por CORMIER e PELLEGRINO (2008), a partir das possibilidades para o manejo das águas pluviais, atralendando as funções "verdes" àquelas "azuis" da infraestrutura.

Autilização de tecnicas que retomem os processos naturais de manejo local das águas de chuva vem sendo aplicada e desenvolvida em vários países, tais como Low Impact Development - LID (EUA), Sustainable Urban Dreinage Systems- SUDS (Reino Unido), Water Sensitive Urban Design - WSUD (Austrália e Reino Unido), Best Management Practicies BMPs (EUA), Low Impact Development- LID (EUA), Sustainable Urban Dreinage Systems- SUDS (Reino Unido), Water Sensitive Urban Design - WSUD (Austrália e Reino Unido), Best Management Practicies BMPs (EUA). Há também exemplos focados na recuperação ambiental e urbana de várzeas, originalmente ocupadas por vias, tais como: Madrid Rio (West 8, Madri, Espanha); Mill River Park (OLIN, Stamford, EUA); ISAR-Plan (State Office of Water Management Munich, Munique, Alemanha), dentre outros.

A partir do entendimento dos desafios infraestruturais urbanos e das possibilidades de retomarmos qualidades ambientais perdidas durante o processo de urbanização, o presente estudo utilizará métodos para identificar avenidas em fundo de vale com potencial para receber Infraestruturas Verde- Azul. Futuramente, cada uma das avenidas com maior potencial poderá ser analisada por critérios específicos a fim de serem consideradas particularidades econômicas, sociais, culturais e do próprio uso e ocupação do solo a partir tanto do recorte geográfico das bacias hidrográficas às quais pertencem quanto dos limites geopolíticos municipais do bairro, distrito e sub- prefeitura. Os critérios utilizados neste estudo inicial são apresentados em seguida. 


\section{MÉTODOS}

A partir de manipulacões por geoprocessamento, primeiramente foram feitas análises territoriais na escala da cidade de São Paulo quanto à localização dos córregos, abertos ou não, do sistema viário e avenidas instaladas em áreas de fundo de vale, além da localização das áreas verdes representadas pelos parques municipais e estaduais, Unidades de Conservação (UC) e de áreas demarcadas pela Secretaria do Verde e do Meio Ambiente (SVMA) como área de reservas da Mata Atlântica.

O segundo passo foi adaptar a metodologia proposta por BENEDICT e MCMAHON (2006) quanto à identificação hubs, sites e links na área de transecto. De acordo com os autores, hubs são áreas verdes capazes de ancorar uma rede de Infraestrutura Verde, promovendo fluxos ecossistêmicos, espaço para a vida selvagem de animais e desenvolvimento da flora e atraindo também atividades de lazer. Sites são áreas verdes menores que os hubs e podem não ser integradas a estes, porém ainda são capazes de promover serviços ecossistêmicos e de valor social. Links são as estruturas que garantem a unidade do sistema, pois são essenciais para manter ativos os processos ecológicos entre os hubs.

Esse método, focado inicialmente numa análise conservacionista espacial na escala de regiões, foi adaptado para ser aplicado na área urbana do estudo. Assim, hubs foram denominados pólos, sites são chamados de fragmentos e links representam as conexões, (Figura 4).

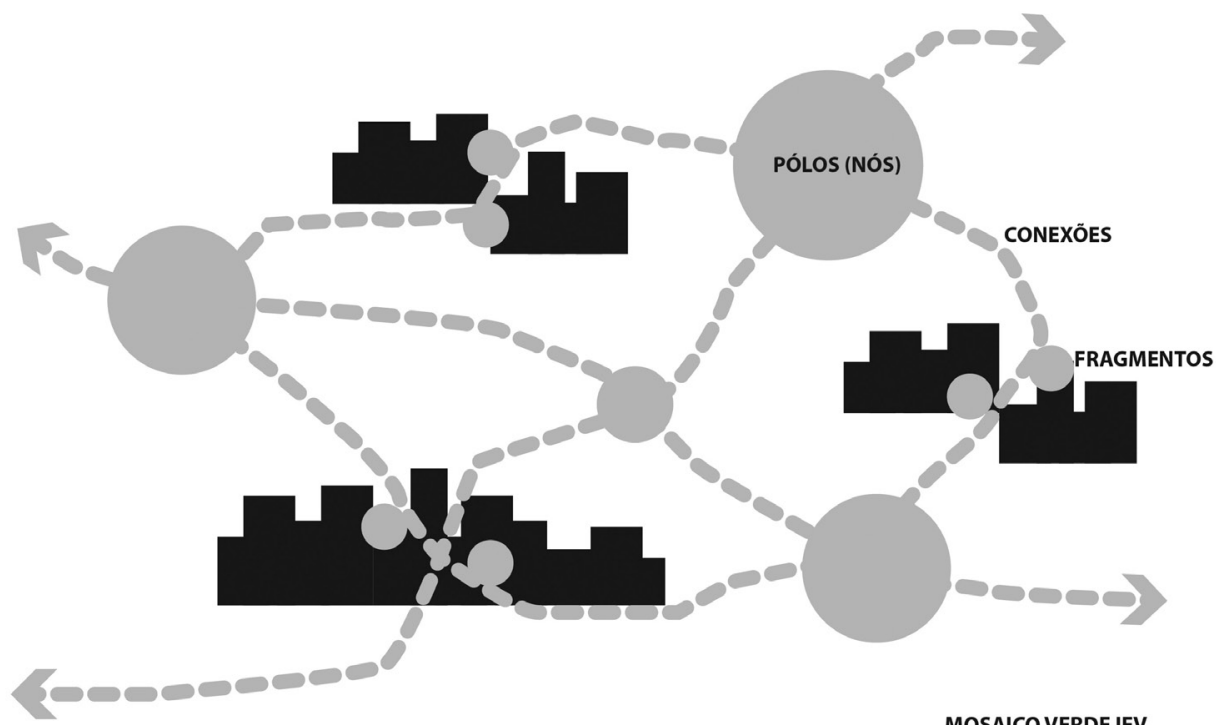

MOSAICO VERDE IEV
Figura 04 - Esquema adaptado "Mosaico Verde"- Pólo, Fragmento, Conexão. Fonte: Marques, T. (2017, p. 228) 
A conectividade, seja física, de processos ou fluxos, é enfatizada por diversos autores focados tanto no desenvolvimento da Infraestrutura Verde, conceitualmente ou como ferramenta de transição (BENEDICT e MCMAHON, 2006; CORMIER e PELLEGRINO, 2008; AHERN, 1995), como por autores que defendem a abordagem de cidade como ecossistema (KOH, 201; TJIALLINGII, S. P., 1993 apud NEWMAN, P.W.G., 1999) ou como parte integral do meio ambiente (FRANCO, M.A.R., 2003). Sendo assim, o método mantém o critério de conectividade como o objetivo de maior relevância.

Quando abordamos a conectividade em uma área extremamente degradada e manipulada ambientalmente como a cidade de São Paulo, este critério passa a ter um caráter investigativo na tentantiva de encontrar espaços abertos que potencialmente possam ser convertidos ou receber elementos capazes de retomar alguns dos serviços ecossistemicos suprimidos pelas atividades urbanas ao serem conectados em rede. Por seu caráter linear e sua localização topográfica, as avenidas em fundo de vale, representam uma tipologia de espaço aberto potencial para reconectar fragmentos verdes que, no caso da cidade de São Paulo, muitas vezes assumem um caráter de quase oásis, ou ilhas verdes em áreas densamente ocupadas por construções e infraestruturas (de mobilidade principalmente).

Seguindo a identificação de Pólos, Fragmentos e Conexões, foram aplicados critérios quanto à condição física dos córregos em relação às avenidas de fundo de vale e o número de possíveis conexões, diretas ou indiretas, que estas estruturas tem às áreas verdes mais expressivas (parques). O objetivo metodológico foi construir uma base de critérios iniciais que auxilie a tomada de decisão quanto à identificação de avenidas em fundo de vale com maior ou menor potencial para receber Infraestruturas Verde-Azul.

\section{ANÁLISES PRELIMINARES: ESCALA SÃO PAULO}

A partir da análise das bases fornecidas pelo portal Geosampa, gerenciado pela Prefeitura Municipal de São Paulo (PMSP), foi possível relacionar os mapas de Drenagem (FCTH, 2015) com a delimitação das Macrozanas Urbana e Rural (SMUL, 2014). A partir desse cruzamento foi gerado o mapa disponível na Figura 05, onde é possível identificar que atualmente cerca de $20 \%$ dos córregos da cidade de São Paulo se encontram subterrâneos e aproximadamente $5 \%$ daqueles ainda abertos estão confinados em canais de concreto. Além disso, verifica- se que praticamente $100 \%$ dos córregos subterrâneos ou canalizados por estruturas de concreto, se encontram nas 
áreas urbanas do município, o que torna largas porções da cidade completamente áridas quanto à presença de água na superfície e também, muitas vezes áridas pela ausência das áreas verdes que originalmente acompanhavam a rede hídrica.

Secas e desmatadas pelas infraestruturas de drenagem e saneamento as planícies aluviais foram ocupadas por uma grande extensão viária como pode ser observado na Figura 06. As análises feitas a partir das informações contidas na Carta Geotécnica (IPT, 1993) e no mapa de Logradouros da cidade (SMUL/ DEINFO, 2014), indicam que cerca de $33 \%$ de todo o sistema viário de São Paulo se encontra atualmente instalado em áreas de várzeas e terras moles que acompanhavam os traçados originais de rios e córregos.

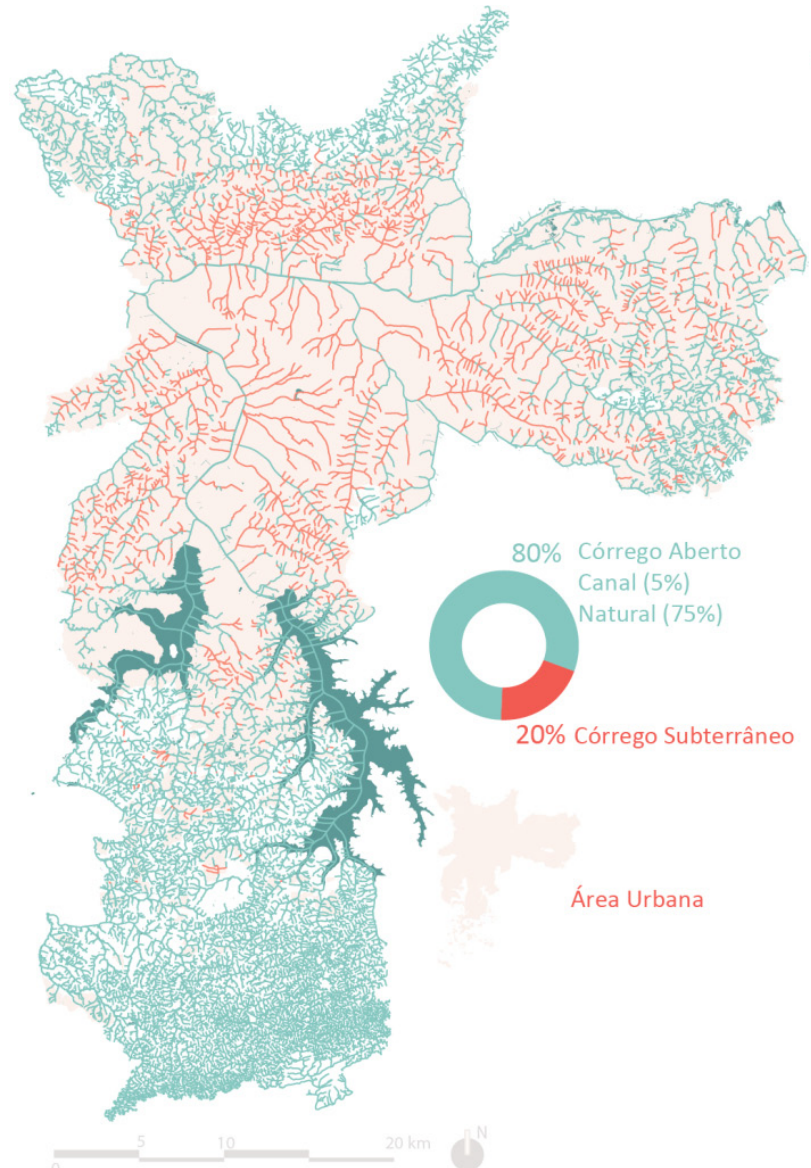

Figura 05 - Mapa de Córregos Abertos e Subterrâneos nas Macrozonas Urbana e Rural.

Elaboracão: autora

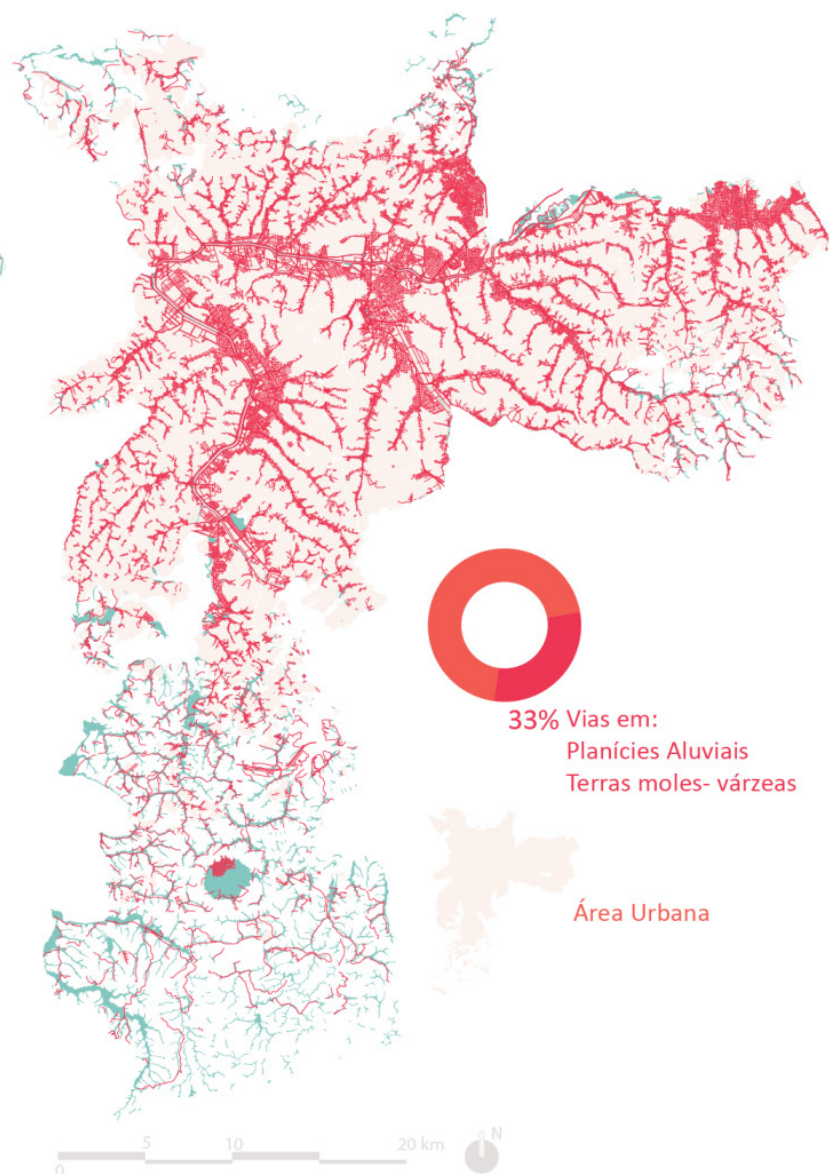

Figura 06 - Mapa de Logradouros em Fundo de Vale. Elaboracão: autora

Na Figura 07 as bases de dados encontradas na Carta Geotécnica de São Paulo (1993), Logradouros, (2014) e Unidades de Conservação, Parques Municipais e Esta- 
duais e Plano Municipal da Mata Atlântica (PMMA), (SVMA, 2016) foram manipuladas. Como resultado destacam-se as avenidas radiais e perimetrais. Pode- se observar que algumas seguem pelas várzeas em direção aos parques estaduais e unidades de conservação encontradas a norte (Serra da Cantareira) e a sul (Serra do Mar), onde também se encontram grande parte dos rios e córregos em estado natural. Como resultado desse processo de espraiamento urbano em direção às importantes áreas verdes e azuis de São Paulo, as ameaças ambientais nessas áreas vêm se tornando cada vez mais intensas. Ao mesmo tempo, a falta de áreas verdes e azuis nas áreas mais consolidadas também afetam diretamente a qualidade ambiental da cidade.

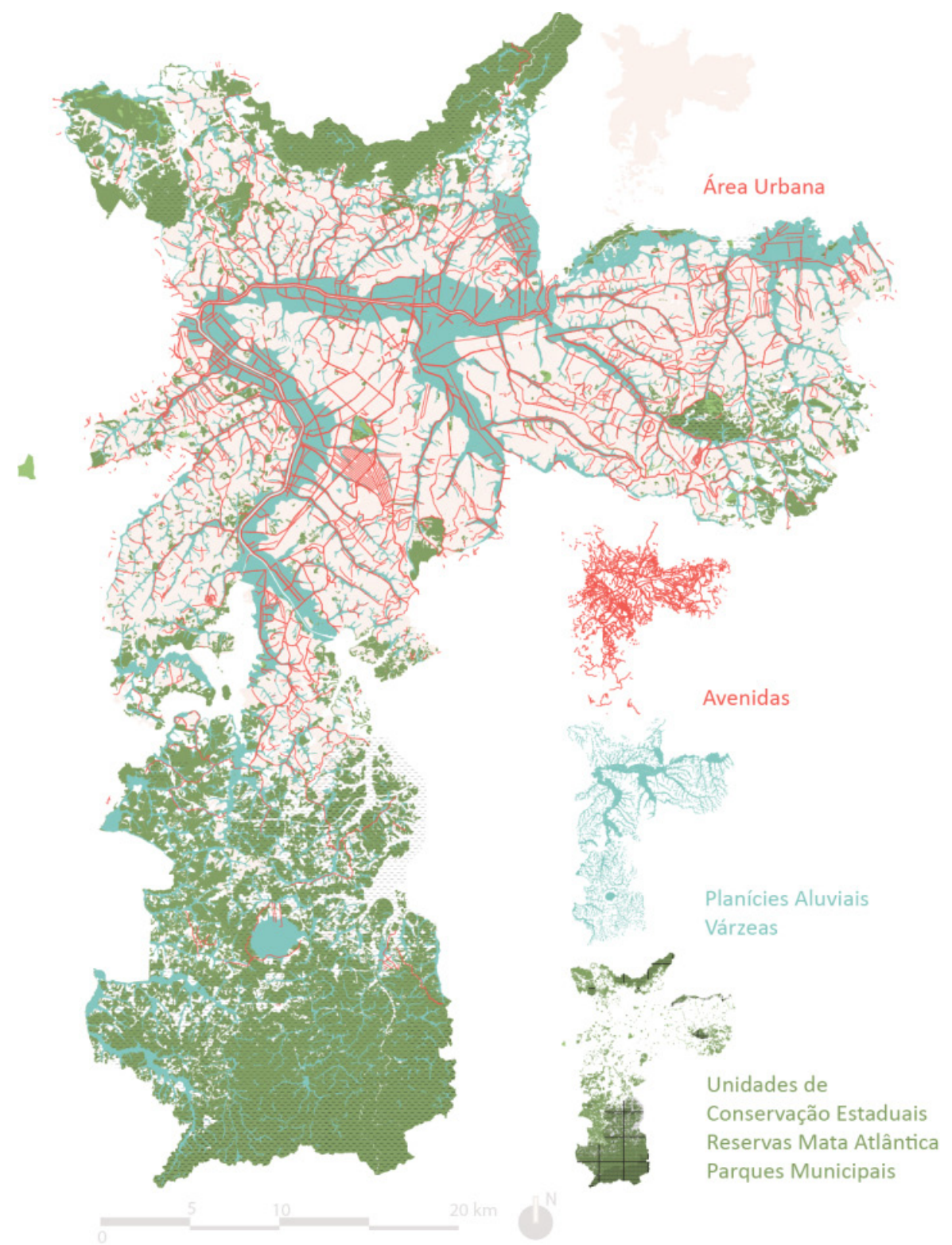

Figura 07 - Mapa de Avenidas, Planícies Aluviais e Parques e Unidades de Consevação. Elaboracão: autora 
Aplicando-se o método "Pólos-Fragmentos- Conexões", pode-se classificar os grandes parques, como o da Cantareira, e as áreas de conservação a norte e a sul, como pólos, onde seria possível ancorar uma rede verde multifuncional tanto de escala regional quanto municipal. Enquanto em escalas regionais a abordagem na escala da paisagem pode ter intensões focadas na conservação e conexão ecossitêmica dos pólos existentes, na escala do municipio o desafio será justamente a busca de caminhos que possam romper a impermeabilidade urbana e conectar os fragmentos isolados. Vale lembrar que uma vez que a conexão com as áreas de conservação é enfatizada, deve-se tomar um cuidado especial, pois espécies vegetais e animais indesejáveis poderão acessar essas áreas, causando danos ao ecossistema (BENEDICT e MCMAHON, 2006).

\section{ANÁLISE DA ÁREA DE ESTUDO: TRANSECTO}

Transecto de Estudo está localizado majoritariamente sobre a zona urbana da cidade de São Paulo (ver Figura 08). Conta com grande parte dos córregos presentes aí em estado subterrâneo ou canalizado aberto além de um sistema viário denso nas áreas de várzea. Os parques municipais encontrados na área estão em sua maioria distrubídos pelo tecido urbano, enquanto os parques estaduais e a UC da Cantareira estão concentrados no extremo norte do transecto. Tais parques podem ser visualizados na Figura 09 em relação às vias localizadas em áreas de Planície Aluvial e Terras moles. Duas ligações entre as vias de várzeas e os parques chamam a atenção, uma delas parte do Parque Ibirapuera até o Parque do Povo, nas áreas marginais do rio Pinheiros, e a outra parte dos parques concentrados no extremo norte em direção à marginal do rio Tietê. O parque da Cantareira e a UC da Cantareira foram considerados como um único parque que poderá ser usado para a ancoragem de uma rede de Infraestrutura Verde regional ou municipal, ou seja, um pólo. Os demais parques, por estarem normalmente imersos ao tecido urbano, foram considerados fragmentos e as avenidas de fundo de vale como potenciais conexões entre essas áreas. 


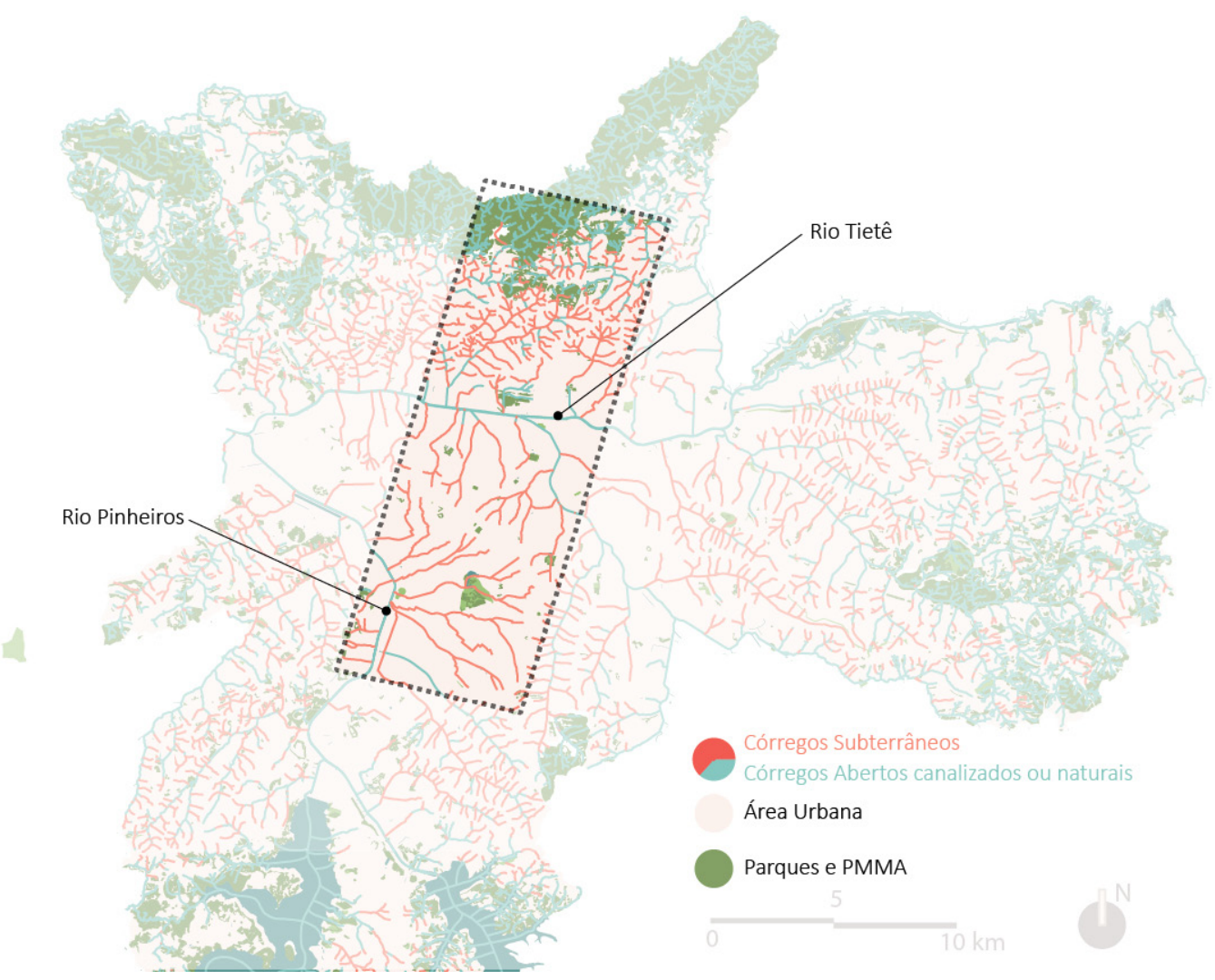

Figura 08 - Mapa de Drenagem no Transecto. Elaboração: autora

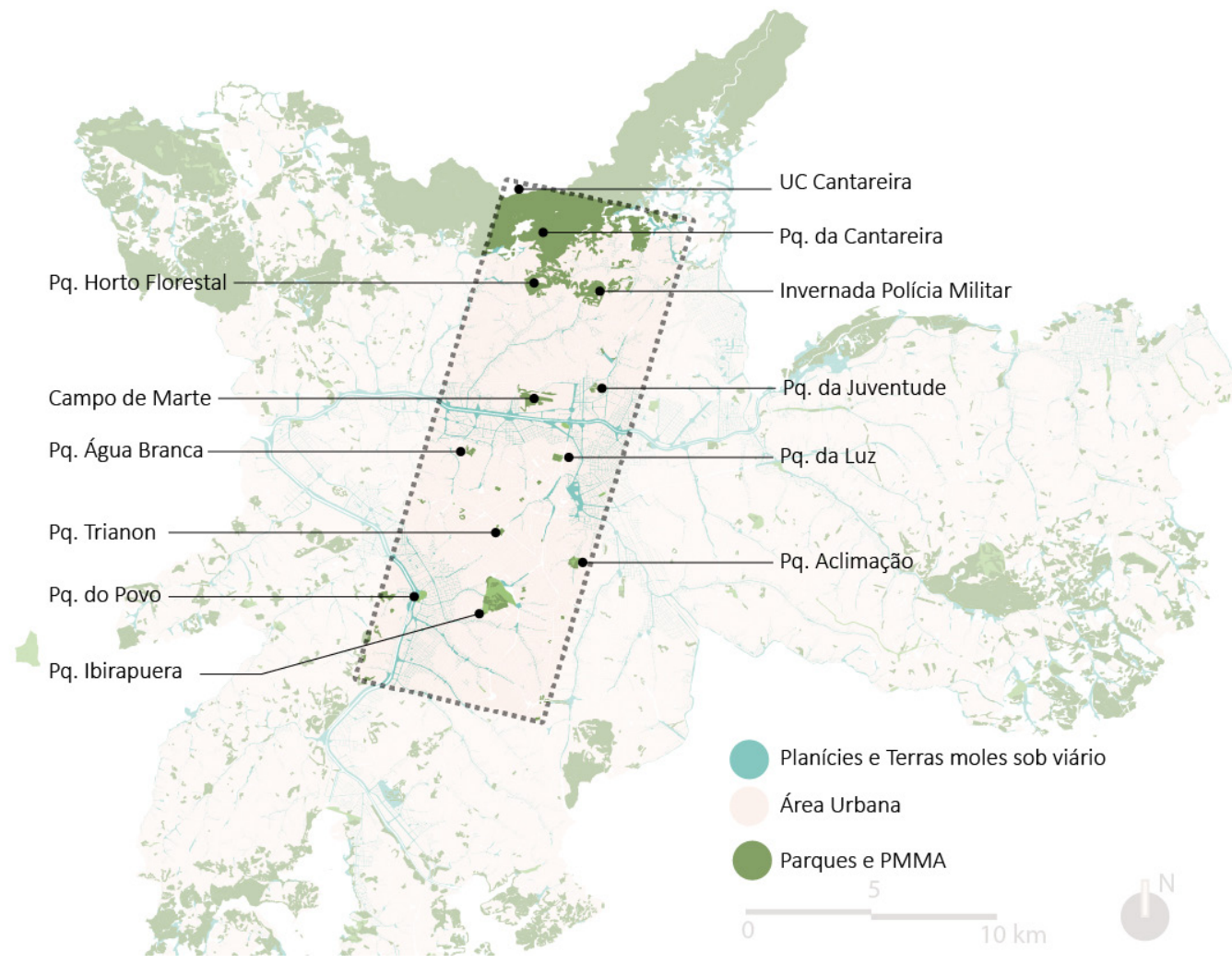

Figura 09 - Mapa de grandes áreas verdes e Viário sobre várzeas. Elaboração: autora 
Ao resultado dessas análises, foi adicionada mais uma camada, com a identificação dos logradouros, o que permitiu listar 14 avenidas em fundo de vale presentes no Transecto. Na Tabela 01, essas vias são listadas, assim como são apresentadas suas relações com os seguintes critérios de análise: Situação do Córrego; Infraestruturas Sobrepostas; Conexão Pólo; Conexão Fragmento; Necessidade de Ancoragem. As "Infraetruturas Sobrepostas" são aquelas tais como, túneis e viadutos sobre a área de córrego e/ ou avenida que podem comprometer ou dificultar a conectividade da Infraestrutura Verde-Azul. O Critério "Necessidade de Ancoragem" baseou-se na ausênsia de pólo ou fragmento em um dos extremos ou em ponto específico da avenida.

Das 14 vias listadas inicialmente, apenas 01 possui potencial "muito bom", 02 potencial "bom", 04 "médio" e as demais "ruim" ou "muito ruim". Para chegarmos a esta classificação foram sugeridos pesos de acordo com a importância de cada critério sendo, 2 a melhor e -1 a pior situação. As "Conexões" direta e indireta com pólos e diretas com fragmentos receberam peso 2, assim como a "Situação Córrego Aberto". As "Conexões Indiretas" com os fragmentos e "Situações de Córrego semi-aberto" receberam peso 1 e as situações de "Córrego Subterrâneo" peso 0. As "Infraetruturas Sobrepostas" e "Necessidade de Ancoragem" foram consideradas com peso negativo, -1, impactando os outros dois critérios.

As categorias "Muito bom", "Bom", "Médio", "Ruim"e "Muito Ruim, foram definidas em 04 momentos:

1. À somatória dos pesos dados ao critério "Situação dos Córregos", foram dadas a seguinte equivalência:

Muito Bom não há no estudo de caso

Bom 2

Médio 1

Ruim $\quad 0$

Muito Ruim -1

A classificação "Muito Ruim", poderia ser atingida caso o córrego estivesse subterrâneo e houvessem interferências de outras Infraestruturas de grande porte, como por exemplo, os túneis da avenida Juscelino Kubitcheck. 
2. À somatória dos pesos dados ao critério "Conexão Pólos" e "Conexão Fragmentos", foram dadas as seguintes equivalências:

$\begin{array}{ll}\text { Muito Bom } & 4 \\ \text { Bom } & 2 \text { ou } 3 \\ \text { Médio } & 1 \\ \text { Ruim } & 0 \\ \text { Muito Ruim } & <-1\end{array}$

A classificação "Muito Ruim" podería ser atingida devido à existência de situações onde há "Necessidade de Ancoragem", como por exemplo nas avenidas Pacaembú, Antártica e Jornalista Roberto Marinho.

3. Após equalizar os critérios "Situação do Córrego", "Conexão Pólos" e "Conexão Fragmentos", seguindo os indicadores descritos nos itens 1 e 2, foi elaborado uma base para a ponderação das classificações geradas anteriormente, conforme segue:

$\begin{array}{ll}\text { Muito Bom } & 4 \\ \text { Bom } & 2 \\ \text { Médio } & 1 \\ \text { Ruim } & -0.5 \\ \text { Muito Ruim } & -1\end{array}$

4. A partir da ponderação dos resultados foi possível gerar os indicadores de potencial:

$\begin{array}{ll}\text { Muito Bom } & \geq 4 \\ \text { Bom } & \geq 3<4 \\ \text { Médio } & \geq 1<3 \\ \text { Ruim } & \geq-1<1 \\ \text { Muito Ruim } & <-1\end{array}$


O resultado da aplicação dessa metodologia pode ser visualizado na Tabela 01. Como apoio para a geração dessa tabela, foram utilizados os mapas dispostos na Figura 10, onde é possível visualizar espacialmente as condições das avenidas em relação às áreas verdes destacadas no transecto.

Tabela 01 - Potencial Avenidas em Fundo de Vale

\begin{tabular}{|c|c|c|c|c|c|c|c|c|c|c|c|}
\hline \multicolumn{2}{|c|}{ Peso } & a & 1 & 2 & \multirow{3}{*}{\begin{tabular}{c|}
1 \\
$\begin{array}{c}\text { Infraestruturas } \\
\text { Sobrepostas }\end{array}$
\end{tabular}} & \multirow{2}{*}{\multicolumn{2}{|c|}{\begin{tabular}{c|c}
2 & 2 \\
Conexăo Pólo
\end{tabular}}} & \multirow{2}{*}{\multicolumn{2}{|c|}{\begin{tabular}{|c|c}
2 & 1 \\
Conexăo Fragmento
\end{tabular}}} & \multirow{3}{*}{\begin{tabular}{|c|}
1 \\
$\begin{array}{c}\text { Necessidade } \\
\text { Ancoragem }\end{array}$ \\
\end{tabular}} & \multirow{3}{*}{ Potencial } \\
\hline No. & \multirow{2}{*}{ Nome Avenida } & \multicolumn{3}{|c|}{ Situaçào Córrego } & & & & & & & \\
\hline MAPA & & Subterrâneo & Semi Aberto & Aberto & & Direta & Indireta & Direta & Indireta & & \\
\hline 1 & Direiros Humanos & $\mathbf{x}$ & & & & 0 & 1 & 1 & 1 & 1 & bom \\
\hline 2 & Eng Caetano Alvares & & $x$ & & & 0 & 1 & 1 & 1 & 1 & muito bom \\
\hline 3 & $\begin{array}{l}\text { Pedro Leon Schneider/ } \\
\text { Gen. Ataliba Leonel/Luiz } \\
\text { Dumont Villares }\end{array}$ & $\mathbf{x}$ & & & & 0 & 0 & 1 & 2 & 1 & médio \\
\hline 4 & Bráz Leme & $\mathrm{x}$ & & & & 0 & 0 & 1 & 0 & 1 & ruim \\
\hline 5 & Moysés Roysen & & & $\mathrm{x}$ & & 0 & 0 & 0 & 1 & 1 & médio \\
\hline 6 & $\begin{array}{l}\text { Antartica (Trecho até } \\
\text { Ferrovia) }\end{array}$ & $x$ & & & & 0 & 0 & 0 & 0 & 2 & muito ruim \\
\hline 7 & $\begin{array}{l}\text { Pacaembu (Trecho até } \\
\text { Ferrovia) }\end{array}$ & $\mathrm{x}$ & & & & 0 & 0 & 0 & 0 & 2 & muito ruim \\
\hline 8 & $\begin{array}{l}\text { Nove de Julho (Trecho } \\
\text { NORTE)/Tiradentes }\end{array}$ & $x$ & & & $\begin{array}{l}\text {-'Túnel av. } \\
\text { Paulista }\end{array}$ & 0 & 0 & 1 & $1^{{ }^{1}}$ & 0 & médio \\
\hline 9 & Sumaré & $x$ & & & & 0 & 0 & 0 & 1 & 1 & ruim \\
\hline 10 & $\begin{array}{l}\text { Cidade Jardim/ Nove de } \\
\text { Julho (Trecho SUL) }\end{array}$ & $\mathrm{x}$ & & & $\begin{array}{l}\text { *'Tùnel av. } \\
\text { Paulista }\end{array}$ & 0 & 0 & 1 & $1^{* 1}$ & 0 & médio \\
\hline 11 & 23 de Maio (Trecho SUL) & $\mathrm{x}$ & & & & 0 & 0 & 1 & 0 & 1 & ruim \\
\hline 12 & $\begin{array}{l}\text { Juscelino Kubitchek/ } \\
\text { Antonio Joaquim de } \\
\text { Moura Andrade }\end{array}$ & $\mathrm{x}^{22}$ & & & ${ }^{2}{ }^{2} 02$ túneis & 0 & 0 & 2 & 0 & & bom \\
\hline 13 & dos Bandeirantes & $x$ & & & & 0 & 0 & 0 & 1 & 1 & ruim \\
\hline 14 & $\begin{array}{l}\text { Jornalista Roberto } \\
\text { Marinho }\end{array}$ & & & $x^{*^{3}}$ & $\begin{array}{l}\text {-'Monotritho } \\
\text { sobre ärea de } \\
\text { corrego }\end{array}$ & 0 & 0 & 0 & 0 & 2 & ruim \\
\hline
\end{tabular}
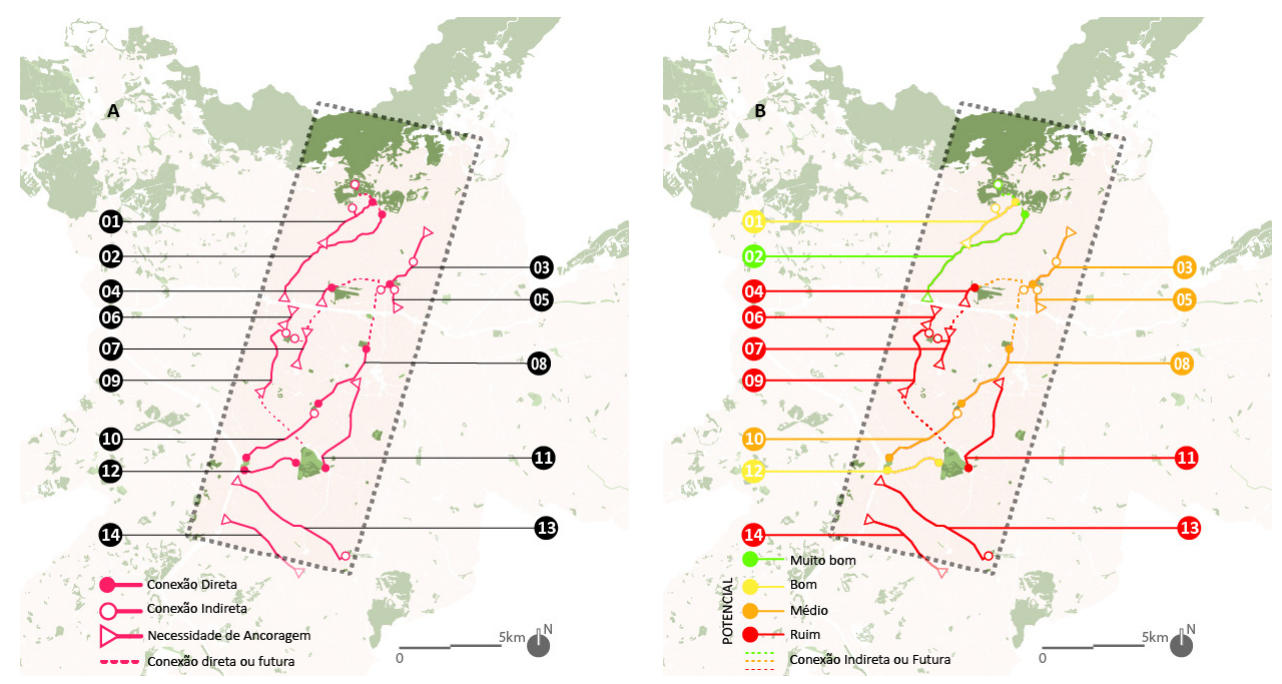

Figura 10 -

A - Avenidas

Selecionadas;

B - Avenidas com

Maior ou Menor

Potencial.

Elaboração: autora 


\section{CONSIDERAÇÕES FINAIS}

Como resultado das análises descritas nesse estudo, foi possível identificar potenciais avenidas de fundo de vale que poderão ser convertidas em eixos de Infraestrutura Verde- Azul, capazes de demonstrar os conceitos defendidos por Waldheim, Koh, Bélanger e Ahern e testar as ferramentas para manejo das águas urbanas através de processos naturais. Os objetivos gerais atendidos pelo estudo foram definidos quanto às conexões físicas entre as áreas verdes existentes e as condições dos córregos nos fundos de vale analisados. A metodologia utilizada no estudo tem carater exploratório, estando aberta para discussões acadêmicas.

O modelo apresentado foi utilizado como um primeiro filtro de critérios para tomada de decisão. Futuramente espera-se adicionar outros, itens considerando por exemplo, fatores abióticos, bióticos, culturais e temporais. Num segundo momento, uma leitura mais detalhada de cada área poderá ser feita caso a caso nas avenidas selecionadas incluindo também as necessidades da população local. Sugere- se que, uma vez focado o estudo, o contexto da bacia hidrográfica seja abordado, pois dessa forma será possível compreender as dinâmicas hidráulicas da área e como a paisagem poderá ser melhor desenhada para manejar as águas das chuvas em suas distintas intensidades, enquanto garante a multifuncionalidade dos eixos de Infraestrutura Verde- Azul, e do sistema criado a partir dessas conexões, evitando possíveis "Trade-offs" entre os serviços ecossistêmicos prestados (Ahern, 1995).

\section{REFERÊNCIAS}

AHERN, J. Green Infrastructure for cities: The spatial dimension. In: NOVOTNY, V; Greenways as a planning strategy. Landscape and Urban Planning 33, p. 131-155. 1995.

BROWN, P. (Orgs.). Cities of the Future: Towards integrated sustainable water landscape management. Londres: IWA Publishing, 2007.

BÉLANGER, P. Landscape Infrastructure, Urbanism beyond Engineering. Wageningen University, Tese Doutoral, 2013. 
BENEDICT, M. A. e MCMAHON, E. T. Green Infrastructure: Linking Landscapes and Communities. Island Press, Washington DC, 2006.

BRITO, F.e SOUZA, J. Expansão Urbana Nas Grandes Metrópoles, o significado das migrações intrametropolitanas e da mobilidade pendular na reprodução da pobreza. São Paulo em Perspectiva, v. 19, n. 4, p. 48-63, out./dez. São Paulo, 2005.

CORMIER, N. S. e PELLEGRINO, P.R.M. Infra-Estrutura Verde: uma Estratégia Paisagística para a Água Urbana. Paisagem e Ambiente n. 25, São Paulo, p. 127- 142, 2005.

FARR, D. Sustainable Urbanism: Urban Design with Nature. John Wiley \& Sons, New Jersey, 2008.

FRANCO, M. A. R. Desenho ambiental. Uma introdução à arquitetura da paisagem com o paradigma ecológico. São Paulo, Annablume, FAPESP, 2003.

M. A. R. . Infraestrutura Verde para a Resiliência Urbana às Mudanças Climáticas da cidade de São Paulo. FAPESP, 2015.

HERZOG, C.P. e ROSA, L. Z. Infraestrutura Verde: Sustentabilidade e Resiliência para a Paisagem Urbana. Revista Labverde, n. 1, p. 92-115. FAU-USP, São Paulo, 2010.

$\mathrm{KOH}$, J. Ecological Infrastructure: enabling Landscape Urbanism. Lecture at Wageningen University, 2011.

MARQUES, Taícia. A Infraestrutura Verde na Gestão de Energia. In: PELLEGRINO, P. e BECKER, N. (Orgs.). Estratégias para uma Infraestrutura Verde. Cap. 10, p. 211241, Figura 10.9. Ed. Manole. São Paulo. 2017

MCHARG, I. L. Design with Nature. 1969.

NEWMAN, P.W.G. Sustainability and cities: extending the metabolism model.

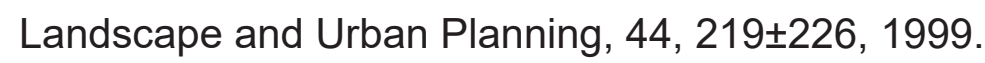

TRAVASSOS, L. R. C. A Dimensão Socioambiental da Ocupação dos Fundos de Vale Urbanos no Município de São Paulo. Universidade de São Paulo, Programa de Pós-Graduação em Ciência Ambiental (PROCAM-USP). São Paulo, 2010. 
TOLEDO, Benedito Lima. Prestes Maia e as Origens da Urbanismo Moderno em São Paulo. São Paulo, Empresa das Artes, 1996. Figura 206

PMSP. Diretrizes Básicas para Projetos de Drenagem Urbana no Município de São Paulo. Elaborado pela Fundação Centro Tecnológico de Hidráulica, 1999.

WALDHEIM, C. (editor). Landscape Urbanism Reader. 2006.

\section{SITES CONSULTADOS}

Geosampa: Mapas em formato Shape- Projeção SIRGAS 2000.

Acessado em 01/ 05/ 2017. Disponível em:

http://geosampa.prefeitura.sp.gov.br/PaginasPublicas/_SBC.aspx

IPCC. Acessado em 05/12/ 2014. Disponível em: http://www.ipcc.ch/ 